\title{
Evaluation of the Effectiveness of the Risk Minimization Measures of Sodium Oxybate in the European Union
}

\author{
Alex Iranzo ${ }^{1} \cdot$ Pedro Serralheiro $^{2}$ Jan-Christof Schuller ${ }^{3} \cdot$ Anne-Françoise Schlit $^{3} \cdot$ Jürgen W. G. Bentz ${ }^{3}$
}

Published online: 28 September 2020

(c) The Author(s) 2020

\begin{abstract}
Background Sodium oxybate $\left(\right.$ Xyrem $\left.^{\circledR}\right)$, approved by the European Medicines Agency (EMA) for narcolepsy with cataplexy, is only available through risk mitigation programs due to potential adverse effects including respiratory and central nervous system depression, neuropsychiatric events, and misuse.

Objective We report findings from a survey evaluating effectiveness of the European Union Xyrem ${ }^{\circledR}$ Risk Management Plan (RMP).

Patients and Methods A cross-sectional, online, multiple-choice survey was distributed to randomly selected healthcare professionals (HCPs) from six European countries (April 2016-May 2018). Eligibility criteria: current/potential Xyrem ${ }^{\circledR}$ prescriber and/or sleep disorder specialist; contact information available; on the Xyrem ${ }^{\circledR}$ RMP educational materials mailing list. Primary outcome: proportion of respondents answering each question correctly $(<50 \%$ responses correct $=$ unsatisfactory comprehension, $50 \%$ to $<70 \%=$ satisfactory, $\geq 70 \%=$ excellent), with precision assessed using $95 \%$ confidence intervals (CIs). Results Of the 709 HCPs contacted, 601 did not agree to take part, 108 were screened with 35/108 eligible for inclusion; 31 HCPs completed the survey. Of the 31 respondents, 29 (93.5\%; 95\% CI 84.4-100.0) reported receiving Xyrem ${ }^{\circledR}$ safety information, commonly from a sales representative, EMA Summary of Product Characteristics (SmPC), or educational meeting; only $9 / 31(31.0 \%$; $14.3-50.0)$ recalled receiving mailed educational materials. The number of HCPs answering dosing-related questions correctly ranged from $24 / 31$ to $31 / 31$. All Xyrem ${ }^{\circledR}$ contraindications were correctly identified by 26/31 (83.9\%; 70.0-96.7) respondents. All respondents 'always' or 'sometimes' completed SmPC recommended activities upon treatment initiation. The majority indicated signs of abuses/misuse/diversion $(23 / 31 ; 74.2 \% ; 58.6-88.0)$ and criminal use $(23 / 31 ; 74.2 \%$; 59.4-89.3) should be monitored at follow-up.

Conclusions These data demonstrate the importance of providing a range of educational materials. However, the low sample size limits interpretation; increased HCP engagement would improve understanding of how best to develop educational materials.
\end{abstract}

European Post-Authorization Study (PAS) register number EUPAS15024.

Electronic supplementary material The online version of this article (https://doi.org/10.1007/s40801-020-00212-9) contains supplementary material, which is available to authorized users.

\footnotetext{
Jürgen W. G. Bentz

juergen.bentz@ucb.com

1 Neurology Service, Hospital Clinic, Barcelona, Spain

2 UCB Pharma, Lisbon, Portugal

3 UCB Pharma, Brussels, Belgium
}

\section{Key Points}

Prescribers participating in the study had excellent knowledge of Xyrem ${ }^{\circledR}$ use for narcolepsy with cataplexy.

Educational programs should include a range of interventions of varying format; face-to-face educational interventions may be more effective than written guidance.

Greater engagement from healthcare professionals is needed to improve educational interventions. 


\section{Introduction}

Narcolepsy with cataplexy affects around $0.02 \%$ of adults, both globally and in Europe [1,2]. Narcolepsy is a chronic neurological disorder characterized by daytime sleepiness that can be associated with symptoms of sleep paralysis, hallucinations, and frequent movement and awakening during sleep [3]. Cataplexy involves the sudden loss of muscle tone triggered by emotions $[1,4]$. The disorder commonly has pediatric onset, but is often not diagnosed until adulthood [5, 6]. Persisting throughout a patient's lifetime, this disorder can considerably affect education, employment, and personal life, in addition to increasing the risk of driving-related accidents [7-11].

There is currently no cure, and patients are advised to implement behavioral modifications alongside lifelong pharmacological management $[12,13]$. Although a range of pharmacologic therapies are available for the symptomatic treatment of excessive daytime sleepiness [13], only two treatments, sodium oxybate and pitolisant hydrochloride, are approved by the European Medicines Agency (EMA) for the treatment of narcolepsy with cataplexy in adults $[14,15]$. During safety evaluation, several 'important identified risks' have been associated with sodium oxybate treatment, including respiratory and CNS depression, and neuropsychiatric events such as depression and suicidality $[14,16]$. Due to depression of the CNS, and the potential for abuse and misuse, sodium oxybate, marketed as Xyrem ${ }^{\circledR}$, is only available through risk evaluation mitigation programs, and patients usually receive extensive education on usage $[16,17]$.

As part of the Xyrem ${ }^{\circledR}$ European Union (EU) Risk Management Plan (RMP), a number of risk management measures have been implemented in the EU, including an updated EMA Summary of Product Characteristics (SmPC), and a program at the point of patient care to educate healthcare professionals (HCPs) about the posology of Xyrem ${ }^{\circledR}$ and the important serious risks associated with treatment. The educational components of this RMP include a checklist for HCPs to use in clinical practice, a 'frequently asked questions' patient information sheet, a How to Take Xyrem ${ }^{\circledR}$ brochure and a patient alert card (Supplementary Figs. 1-4, see electronic supplementary material [ESM]).

Here, we report findings from a survey of HCPs that was carried out to evaluate the effectiveness of these risk management measures. The objectives were to assess prescribers' awareness of the educational materials, assess whether prescribers self-reported their behavior/practices with respect to minimizing the important identified risks, and to assess prescribers' knowledge of the posology of Xyrem ${ }^{\circledR}$.

\section{Material and Methods}

\subsection{Study Design and Setting}

A cross-sectional, online survey was designed to evaluate prescribers' understanding of the appropriate use and significant risks of Xyrem ${ }^{\circledR}$. HCPs were selected from a list of prescribers from Belgium, Germany, Italy, Spain, Sweden, and the United Kingdom (UK). These countries were preselected to include various population sizes and healthcare systems. After removing duplicate names from the lists for each selected country, names were assigned a random number and the lists re-ordered based on number assignment. A sample of names from the randomized list in each country was then selected for recruitment. An additional sample was selected during the recruitment and data collection period to increase the number of participants. Ethics approval was sought and granted as required by the individual countries.

Data collection took place between 1 April 2016 and 1 May 2018; the length of time between latest distribution of education materials and data collection was variable, ranging from $\sim 2$ years (Belgium) to 2 months (Spain) (Supplementary Table 1, see ESM). HCPs were contacted through a combination of phone calls and email invitations, depending on HCP preference and available contact details. A reminder email was sent, or a follow-up call made, within 3 weeks of the first invitations if no response was received. All HCP outreach, including invitations to take part, the survey, and any reminder letters, were provided in the language of the local country. Each invitation included a unique code, which was deactivated after use to ensure that the invitation was used only once. The electronic data capture system for data collection encrypted all identifiable information; respondent identifiers were stored separately from the survey responses. All participants who completed the survey received a thank you note and a small payment.

\subsection{Study Participants}

Survey participation was voluntary, and the survey began with a question indicating the HCP's agreement to participate in the survey. HCPs eligible for inclusion were either currently prescribing Xyrem ${ }^{\circledR}$, had the potential to prescribe $\mathrm{Xyrem}^{\circledR}$, and/or were sleep disorder specialists with available contact information. Survey participants must also have been included in the Xyrem ${ }^{\circledR}$ RMP educational materials mailing list.

HCPs were not eligible to take the survey if they met any of the following criteria: currently an employee, or their immediate family member was an employee, of the Xyrem ${ }^{\circledR}$ manufacturer, United Bioscience Corporation (advisor on survey design), Luto (Leeds University 
Testing Organisation; survey administrator), the EMA, or the National Competent Authority.

\subsection{Survey Structure, Outcomes and Analysis}

The survey was composed of 18 multiple-choice and closedended questions; no open-ended questions were included (Supplementary Table 2, see ESM). Questions were formatted to avoid having the same affirmative answer for all desired responses and multiple-choice questions included distractor or intentionally incorrect response options. To minimize bias, questions were programmed to ensure that they were asked in an appropriate sequence. Respondents could not return to a previously answered question and could not skip ahead; to complete the survey, all questions had to be answered. To further minimize bias, lists of response options were presented in a randomized order.

The primary outcome was the proportion of participants who returned a completed survey giving a correct response for each individual question, consistent with the Xyrem ${ }^{\circledR}$ SmPC. Point estimates for the proportion of respondents giving correct answers, and the associated $95 \%$ confidence intervals (CIs), were calculated for each question. A rate of correct responses of less than 50\% was considered unsatisfactory comprehension, a rate of at least $50 \%$ but less than $70 \%$ was considered satisfactory, and a rate of $70 \%$ or more was considered excellent. HCP demographic information was collected at the end of the survey to further characterize the respondent population in addition to those who chose not to participate. Data were stratified by country and medical specialty (two recruitment routes were used in Germany; these were combined for subgroup analysis by country).

Quality checks were performed on the raw data to confirm that answers were being recorded for all questions as expected, the survey was working correctly, and all respondents were eligible for inclusion.

\subsection{Statistical Analysis}

The survey was designed with the aim of reaching 200 Xyrem ${ }^{\circledR}$ prescribers across all six countries combined, although strict power requirements were not specified in the protocol. The number of HCPs within each country who were initially contacted was proportional to the population size: Germany, 30\%; UK, 23\%; Italy, 22\%; Spain, 17\%; Belgium, $4 \%$; Sweden, $4 \%$.

The precision of the level of understanding estimates was assessed using 95\% CIs calculated for the sample size, with lower sample sizes accompanied by wider $95 \%$ CIs (Supplementary Table 3, see ESM). Missing data were accounted for using either valid percentages or classification as 'other' for the missing question, and the individual was included for all analyses.

\section{Results}

\subsection{Survey Participants}

Of the 709 HCPs who were contacted, 601 did not agree to take part (due to reasons including unavailability and inability to obtain employer permission) or did not respond; $108 \mathrm{HCPs}$ who agreed to take part were sent a survey, 35 of whom were eligible for inclusion. Of these, 31 HCPs completed the survey (Fig. 1). Around two thirds of respondents were male, and $44.8 \%$ had spent more than 20 years working in medical practice. The most common medical specialties were sleep specialists and neurologists (Table 1). The majority of respondents $(29.0 \%)$ were from Germany, with the least $(6.5 \%)$ from the UK (Table 1); this did not reflect the proportions of HCPs from different countries initially contacted (Fig. 1).

\subsection{Prescriber Knowledge of Correct Dosing and Contraindications}

Overall, the level of knowledge of the respondents with regards to dosing as per the EMA SmPC was considered excellent: all respondents knew that the second dose should be taken no sooner than $2.5 \mathrm{~h}$ and no later than $4 \mathrm{~h}$ after the first dose, 30/31 (96.8\%; 95\% CI 89.7-100.0) recognized that the starting dose of $\mathrm{Xyrem}^{\circledR}$ should not be divided into four equal parts, 29/31 (93.5\%; 95\% CI 83.9-100.0) were aware of the recommended time interval between dose increments and titration, 27/31 (87.1\%; 95\% CI 74.2-96.9) were aware that single doses of $4.5 \mathrm{~g}$ Xyrem $^{\circledR}$ should not be given unless the patient has been titrated previously to that dose, and 28/31 (90.3\%; $95 \%$ CI 78.1-100.0) respondents understood that patients should not be instructed to take Xyrem ${ }^{\circledR}$ before beginning their daily activities in the morning. Additionally, 25/31 (80.6\%; 95\% CI 65.6-93.3) knew the recommended starting dose of Xyrem ${ }^{\circledR}$, and 24/31 (77.4\%; 95\% CI 60.7-91.4) correctly identified the statement "if a patient discontinues Xyrem ${ }^{\circledR}$ for more than 14 consecutive days, titration should be started from the highest previous dose taken" as false.

The majority $(26 / 31 ; 83.9 \%$; 95\% CI $70.0-96.7)$ of respondents correctly identified all of the contraindications for prescribing Xyrem ${ }^{\circledR}$, and the number of HCPs who knew which patient characteristics should be evaluated before prescribing $\mathrm{Xyrem}^{\circledR}$ was $30 / 31$ for history of depression and/or suicide attempt $(96.8 \%$; $95 \%$ CI $89.7-100.0), 28 / 31$ for underlying respiratory disorder (90.3\%; 95\% CI 78.1-100.0), 27/31 for history of/potential for drug abuse $(87.1 \%$; $95 \%$ CI $74.1-97.0)$ and $25 / 31$ for 


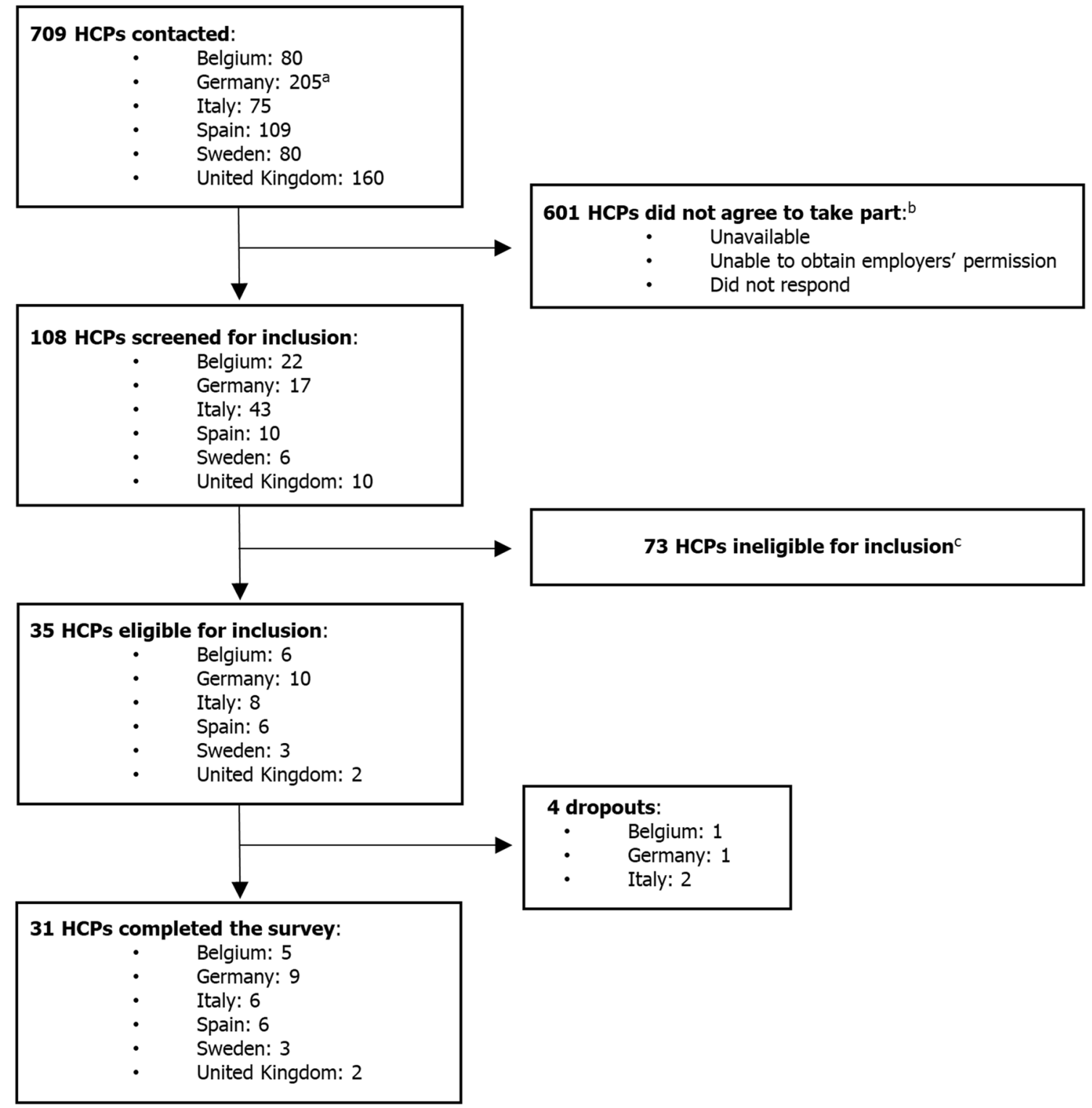

Fig. 1 Flow diagram of HCP survey respondents. ${ }^{a}$ In Germany, 627 HCPs were initially contacted, following which the approach to recruitment was modified and the agreement to participate was made available online, only HCPs contacted after this amendment $(N=205)$

history of epileptic seizures (80.6\%; 95\% CI 65.4-93.5). Additionally, 24/31 (77.4\%; 95\% CI 61.5-90.9) respondents identified correctly that patients should be counselled not to drive or operate machinery for at least $6 \mathrm{~h}$ after taking Xyrem ${ }^{\circledR}$ and $24 / 31$ (77.4\%; 95\% CI 61.3-90.9) correctly identified the medical conditions for which a dietary recommendation to reduce sodium intake should be made.

A high proportion of respondents knew that Xyrem ${ }^{\circledR}$ should not be used in combination with medications that can cause drowsiness $(26 / 31 ; 83.9 \%$; 95\% CI 71.0-96.7), CNS depression $(28 / 31 ; 90.3 \%$; 95\% CI 78.1-100.0), or respiratory depression $(28 / 31 ; 90.3 \%$; $95 \%$ CI $78.8-100.0)$. were included in these analyses; ${ }^{\mathrm{b}} \mathrm{A}$ full breakdown of the numbers and reasons why HCPs did not agree to take part is not available; ${ }^{\mathrm{c}} \mathrm{A}$ full breakdown of the numbers and reasons why HCPs were ineligible for inclusion is not available. $H C P$ healthcare professional

However, 18/31 (58.1\%; 95\% CI 38.7-75.7) incorrectly identified ability to stay awake after a meal as a patient characteristic to evaluate, and $17 / 31(54.8 \%$; $95 \% \mathrm{CI}$ 36.7-71.9) incorrectly stated that Xyrem ${ }^{\circledR}$ should not be used in combination with medications that can cause increased appetite. Furthermore, only 10/31 (32.3\%; 95\% CI 17.2-48.5) had knowledge of the correct body mass index (BMI) threshold at which patients should be closely monitored due to higher risk of sleep apnea $(>40 \mathrm{~kg} /$ $\left.\mathrm{m}^{2}\right)$; the majority $(14 / 31 ; 45.2 \%$; $95 \%$ CI $29.0-63.3)$ of respondents selected $>30 \mathrm{~kg} / \mathrm{m}^{2}$ in answer to this question. 
Table 1 Characteristics of survey respondents

All $(N=31)$

Country, $n$ (\%)

Belgium

$5(16.1)$

Germany

9 (29.0)

Italy

$6(19.4)$

Spain

6 (19.4)

Sweden

$3(9.7)$

UK

$2(6.5)$

Gender $^{\mathrm{a}}, \boldsymbol{n}(\%)$

Male

19 (65.5)

Female

$10(34.5)$

Years in medical practice ${ }^{\mathrm{a}}, \boldsymbol{n}(\%)$

$<3$ years

$0(0.0)$

3-5 years

$0(0.0)$

6-10 years

3 (10.3)

11-15 years

7 (24.1)

16-20 years

4 (13.8)

$>20$ years

$13(44.8)$

Prefer not to say

2 (6.9)

Medical specialty ${ }^{\mathrm{b}}, \boldsymbol{n}(\%)$

Neurologist

12 (38.7)

Sleep specialist

14 (45.1)

Pneumologist

1 (3.2)

Neuropsychiatrist

$1(3.2)$

General practitioner

$0(0.0)$

Other

$3(9.7)$

Predominant medical practice for prescribing Xyrem ${ }^{\circledR}{ }^{\mathrm{a}}, \boldsymbol{n}(\%)$

Public practice

$19(65.5)$

Private practice

$0(0.0)$

Mix of private and public

3 (10.3)

Other

7 (24.1)

Missing data were classified as 'other' and included for all analyses $n$ number of respondents

${ }^{a}$ Two respondents did not provide an answer for these items

${ }^{\mathrm{b}}$ Two respondents did not provide an answer for this item

\subsection{Prescriber Awareness of Risk Minimization Checks for Patients Taking Xyrem ${ }^{\circledast}$}

Overall, 8/31 respondents could not recall receiving a Xyrem ${ }^{\circledR}$ Healthcare Provider Checklist, and five respondents indicated that they had not used the checklist in the past 12 months; only 18 answered that they 'always' or 'sometimes' used the checklist (Table 2). Generally, respondents indicated that patients should be reviewed for factors that could influence Xyrem ${ }^{\circledR}$ treatment such as concomitant medications, BMI, and additional risks of respiratory depression prior to treatment initiation (Fig. 2a). The majority of respondents indicated that signs of abuses, misuse or diversion, and signs of criminal use, should be monitored at a follow-up visit following treatment initiation (Fig. 2a).

All respondents 'always' or 'sometimes' completed the activities that are recommended upon treatment initiation with their patients; the majority of respondents indicated 'always' (Fig. 2b).

\subsection{Receipt of Information on the Safety Profile and Safe Use of Xyrem ${ }^{\circledast}$}

Of the 31 respondents, 29 had received information that provided guidance on the safety profile and safe use of Xyrem ${ }^{\circledR}$ (Table 3). Most commonly, this information had been provided by Xyrem $^{\circledR}$ sales representatives (13/31), the SmPC (11/31), or a manufacturer-sponsored educational meeting $(10 / 31)$ (Table 3).

\section{Discussion}

This study used a cross-sectional, online survey to evaluate the effectiveness of the risk management measures being implemented as part of the EU RMP for Xyrem ${ }^{\circledR}$. Overall, the majority of questions were correctly answered by over $70 \%$ of respondents. Knowledge of the SmPC was only considered unsatisfactory for one item, regarding the BMI at which patients should be monitored most closely. However, the results indicate that HCPs may be taking more conservative, precautionary measures in practice.
Table 2 HCP use of the Xyrem ${ }^{\circledR}$ Healthcare Provider Checklist

\begin{tabular}{|c|c|c|}
\hline & $n$ & $\%$ Respondents, $(95 \% \mathrm{CI})$ \\
\hline \multicolumn{3}{|c|}{$\begin{array}{l}\text { When treating patients with Xyrem }{ }^{\circledR} \text {, how often in the past } 12 \text { months did you use the Xyrem } \\
\text { Healthcare Provider Checklist? }(N=31)\end{array}$} \\
\hline Always & 7 & $22.6(7.1-39.3)$ \\
\hline Sometimes & 11 & $35.5(18.2-53.1)$ \\
\hline Never & 5 & $16.1(3.3-30.3)$ \\
\hline I don't recall receiving checklist & 8 & $25.8(10.8-43.3)$ \\
\hline
\end{tabular}

$C I$ confidence interval, $H C P$ healthcare professional, $n$ number of respondents 
Fig. 2 Prescriber awareness of risk minimization checks for patients receiving Xyrem ${ }^{\circledR}$. a Review of patients prior to and during treatment. b Guidance provided to patients by prescribers when initiating treatment. Error bars show $95 \%$ confidence intervals. $B M I$ body mass index, $n$ number of respondents. ${ }^{\text {a Miss }}$ ing data for one patient $(N=30)$
How often should the following activities be performed when you see a patient being treated with $\mathrm{Xyrem}^{\circledR}$ ? ( $\mathrm{N}=31$ )

- Prior to initiation 鴹 At treatment initiation $\boldsymbol{Z}$ Follow-up visit $\square$ Never $\equiv$ I don't know

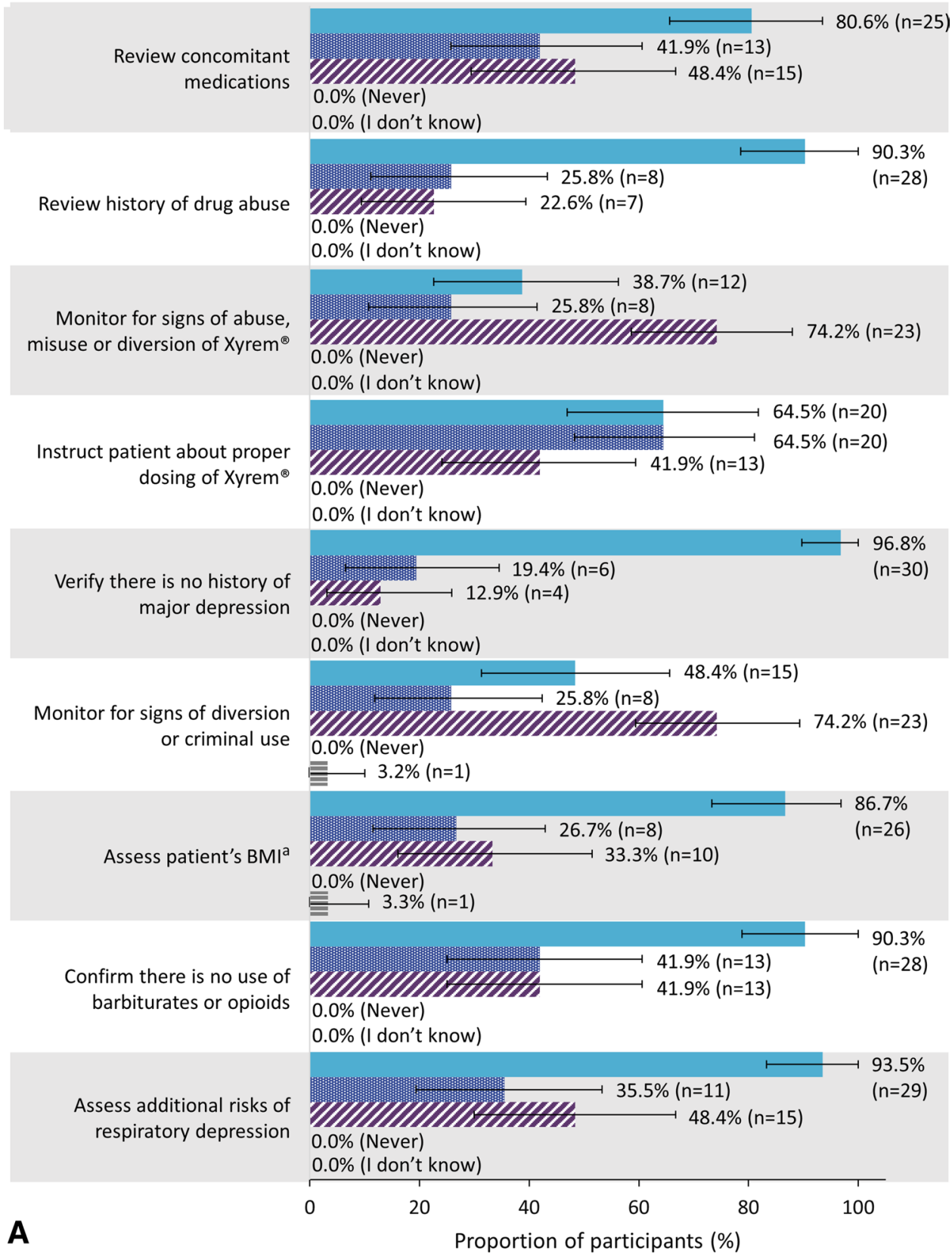

Although all HCPs selected for inclusion in the survey had been sent the RMP educational materials, only 7 of the 31 respondents reported that they had 'Always' used the Xyrem ${ }^{\circledR}$ Healthcare Provider Checklist when prescribing in the past 12 months. Use of the checklist is not mandatory, so it is possible that use varies according to HCP experience or $\mathrm{HCP}$ opinion of the checklist. Exploration of this in future studies would allow the checklist to be optimized according to HCP preference, and instructions for use improved. 
Fig. 2 (continued)

How often do you do each of the following with your patients when initiating treatment with Xyrem ${ }^{\circledR}$ ? $(\mathrm{N}=31)$
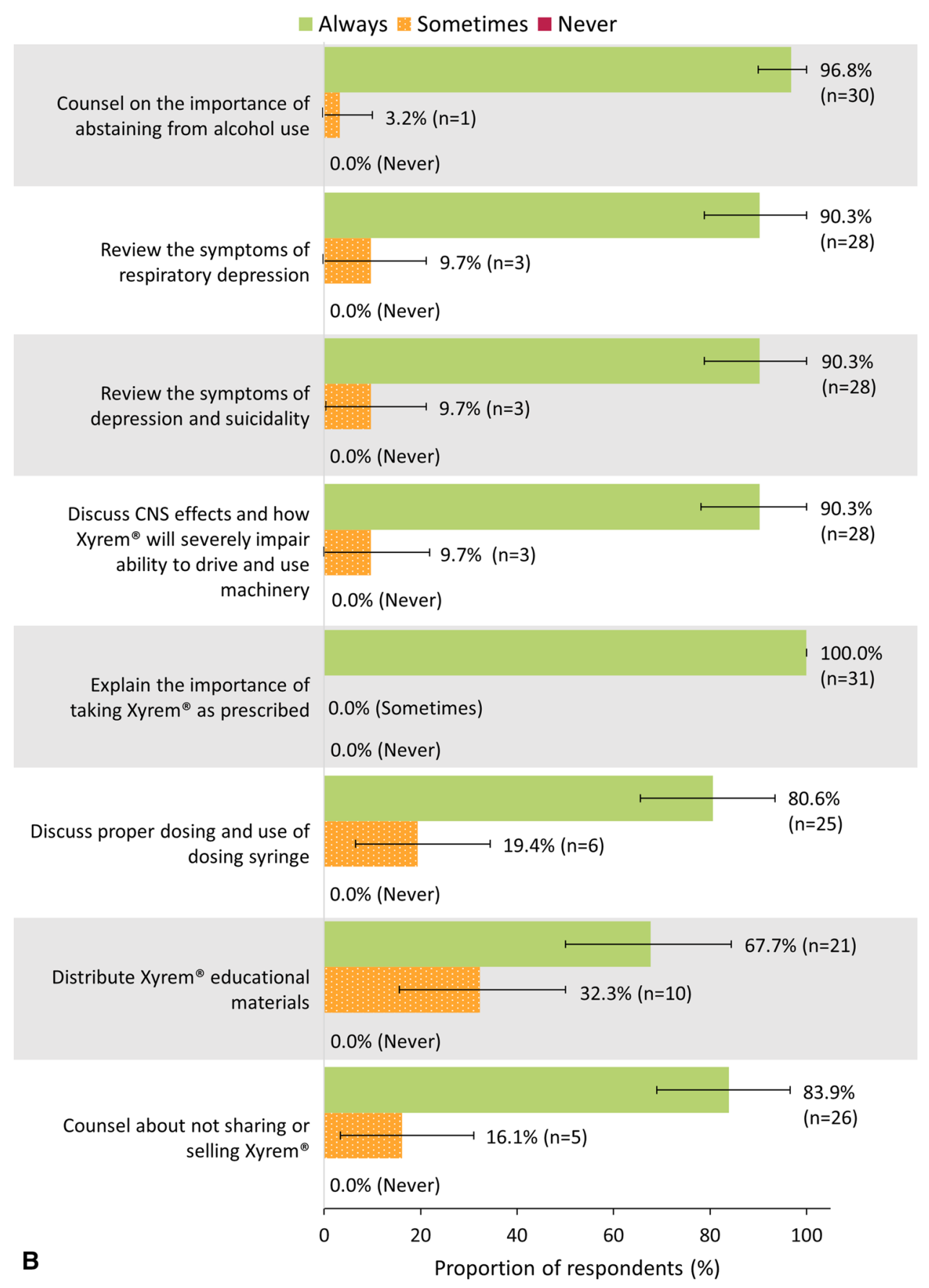

Only 9 of the 31 respondents recalled having received mailed educational materials regarding product safety. In contrast, 29 of the 31 respondents indicated that they had received guidance on the safety profile and safe use of Xyrem $^{\circledR}$, most commonly via a sales representative of the manufacturer, the SmPC, or during attendance at a manufacturer-sponsored educational meeting. In some cases, there was a delay of 1-2 years between latest distribution of the educational materials and the start of data collection, which may explain the low numbers who recalled receiving the mailed materials. Alternatively, it could be that HCPs may be more likely to engage with and recall information given during a face-to-face, interactive intervention, compared with the simple provision of guidelines and checklists. A systematic literature review (SLR) evaluating the effectiveness of educational interventions in the 
Table 3 Guidance provided to prescribers regarding the safe use of Xyrem ${ }^{\circledR}$

$\%$ Respondents, (95\% CI)

\begin{tabular}{|c|c|c|}
\hline $\begin{array}{l}\text { Have you received any information that pro } \\
\text { with cataplexy? }(N=31)\end{array}$ & & ents with narcoleps \\
\hline Yes & 29 & $93.5(84.4-100.0)$ \\
\hline No & 1 & $3.2(0.0-10.0)$ \\
\hline I do not remember & 1 & $3.2(0.0-10.0)$ \\
\hline In what form has this information been pro & & \\
\hline Manufacturer-sponsored educational meeting & 10 & $34.5(16.7-53.3)$ \\
\hline SmPC (summary of product characteristics) & 11 & $37.9(20.0-54.8)$ \\
\hline Journal article & 5 & $17.2(3.8-32.3)$ \\
\hline Mailing of educational materials & 9 & $31.0(14.3-50.0)$ \\
\hline Manufacturer website & 2 & $6.9(0.0-17.2)$ \\
\hline Other health care professionals & 4 & $13.8(3.3-28.1)$ \\
\hline Manufacturer medical information & 7 & $24.1(10.0-40.0)$ \\
\hline Manufacturer sales representatives & 13 & $44.8(26.9-64.3)$ \\
\hline None of the above & 2 & $6.9(0.0-17.2)$ \\
\hline
\end{tabular}

CI confidence interval, $n$ number of respondents

improvement of antibiotic prescribing practices reported similar findings [18]. However, variability in the impact and outcome of interventions has been reported between studies, dependent on factors including the condition being treated and circumstances of treatment [19, 20].

The collection of data of this kind is a regulatory requirement to understand the effectiveness of risk management measures and educational interventions. However, the low response rate here not only limits interpretation of these results, but also prevents the conduct of more in-depth analysis, including subgroup analysis of any differences between countries and medical specialties. The low response rate could be due to many of the contacted HCPs having limited time to complete a survey, or hospital requirements for contracts and other paperwork to be in place prior to participation. Furthermore, the 709 HCPs contacted included any physician able to write a prescription for Xyrem ${ }^{\circledR}$, not only those who routinely treat patients with narcolepsy with cataplexy; this potentially resulted in reduced interest in the survey amongst those contacted. As the public availability of data of this kind will be of increasing importance in the further development of educational materials, improving HCP engagement should be considered for future research.

Alongside the small sample size, a further limitation of this survey is its voluntary nature; although the sample of HCPs invited to participate was randomly selected, the survey respondents who took part were self-selected. Therefore, the results are likely to have a positive bias; for example, those who regularly refer to the risk management materials could be most likely to respond. Additionally, several of the questionnaire items were related, meaning respondents who answered one question correctly would be expected to answer other, related questions correctly.

The survey methodology employed here could have been improved through partnering with a specialist scientific society to improve HCP engagement or undertaking the survey in a controlled setting. However, these methods would present practical considerations requiring additional time and funding.

This survey of $\mathrm{Xyrem}^{\circledR}$ prescribers indicates that the provision of a wide range of educational sources from which HCPs can seek guidance may be important, and that HCPs in general had engaged with the educational materials and guidance received. However, despite the survey being a regulatory requirement and the large number of HCPs initially contacted, there were difficulties engaging HCPs with the study. Increased engagement of HCPs with research of this kind would allow improved understanding of how best to support HCPs from different geographies or medical specialties.

Acknowledgements The authors acknowledge Linda Feighery, Ph.D. CMPP, UCB Pharma Ltd., Slough, UK, for publication coordination and Amelia Frizell-Armitage, Ph.D., and Debbie Nixon, DPhil, from Costello Medical, Cambridge, UK, for medical writing and editorial assistance in preparing this manuscript for publication, based on the authors' input and direction.

\section{Declarations}

Funding UCB Pharma. 
Conflict of interest Alex Iranzo: Consulting fees and other honoraria from UCB Pharma; Pedro Serralheiro, Jan-Christof Schuller, AnneFrançoise Schlit: Employees of UCB Pharma; Jürgen W.G. Bentz: Employee and shareholder of UCB Pharma.

Ethics approval Ethics approval was sought and granted as required by the participating countries.

\section{Consent to participate Not applicable.}

Consent for publication Not applicable.

Availability of data and material Data from non-clinical studies is outside of UCB's data sharing policy.

Code availability Not applicable.

Author contributions Substantial contributions to study conception and design: AI, PS, J-CS, A-FS, and JWGB; contributions to analysis and interpretation of the data: AI, PS, J-CS, A-FS, and JWGB; drafting the article or revising it critically for important intellectual content: AI, PS, J-CS, A-FS, and JWGB; final approval of the version of the article to be published: AI, PS, J-CS, A-FS, and JWGB.

Compliance with ethical standards UCB sponsored the study and the development of the manuscript/publication and reviewed the text to ensure that from a UCB perspective, the data presented in the publication are scientifically, technically, and medically supportable, that they do not contain any information that has the potential to damage the intellectual property of UCB, and that the publication complies with applicable laws, regulations, guidelines and good industry practice. The authors approved the final version to be published after critically revising the manuscript/publication for important intellectual content.

Open Access This article is licensed under a Creative Commons Attribution-NonCommercial 4.0 International License, which permits any non-commercial use, sharing, adaptation, distribution and reproduction in any medium or format, as long as you give appropriate credit to the original author(s) and the source, provide a link to the Creative Commons licence, and indicate if changes were made. The images or other third party material in this article are included in the article's Creative Commons licence, unless indicated otherwise in a credit line to the material. If material is not included in the article's Creative Commons licence and your intended use is not permitted by statutory regulation or exceeds the permitted use, you will need to obtain permission directly from the copyright holder. To view a copy of this licence, visit http://creativecommons.org/licenses/by-nc/4.0/.

\section{References}

1. Dauvilliers Y, Arnulf I, Mignot E. Narcolepsy with cataplexy. Lancet. 2007;369:499-511.

2. Khatami R, Luca G, Baumann CR, et al. The European Narcolepsy Network (EU-NN) database. J Sleep Res. 2016;25:356-64.
3. National Institute of Neurological Disorders and Stroke. Narcolepsy Fact Sheet. https://www.ninds.nih.gov/Disorders/Patie nt-Caregiver-Education/Fact-Sheets/Narcolepsy-Fact-Sheet. Accessed May 2019.

4. Sturzenegger C, Bassetti CL. The clinical spectrum of narcolepsy with cataplexy: a reappraisal. J Sleep Res. 2004;13:395-406.

5. Dauvilliers Y, Montplaisir J, Molinari N, et al. Age at onset of narcolepsy in two large populations of patients in France and Quebec. Neurology. 2001;57:2029-33.

6. Okun ML, Lin L, Mignot E, et al. Clinical aspects of narcolepsycataplexy across ethnic groups. Sleep. 2002;25:27-35.

7. Dodel R, Peter H, Spottke A, et al. Health-related quality of life in patients with narcolepsy. Sleep Med. 2007;8:733-41.

8. Jennum P, Ibsen R, Petersen ER, et al. Health, social, and economic consequences of narcolepsy: a controlled national study evaluating the societal effect on patients and their partners. Sleep Med. 2012;13:1086-93.

9. Philip P, Sagaspe P, Lagarde E, et al. Sleep disorders and accidental risk in a large group of regular registered highway drivers. Sleep Med. 2010;11:973-9.

10. Raggi A, Plazzi G, Ferri R. Health-related quality of life in patients with narcolepsy: a review of the literature. J Nerv Ment Dis. 2019;207:84-99.

11. Smolensky MH, Di Milia L, Ohayon MM, et al. Sleep disorders, medical conditions, and road accident risk. Accid Anal Prev. 2011;43:533-48.

12. Billiard M, Bassetti C, Dauvilliers Y, et al. EFNS guidelines on management of narcolepsy. Eur J Neurol. 2006;13:1035-48.

13. Thorpy MJ, Dauvilliers Y. Clinical and practical considerations in the pharmacologic management of narcolepsy. Sleep Med. 2015;16:9-18.

14. Xyrem Summary of Product Characteristics. https://www.ema. europa.eu/en/documents/product-information/xyrem-epar-produ ct-information_en.pdf. Accessed May 2019.

15. Wakix Summary of Product Characteristics. https://www.ema. europa.eu/en/documents/product-information/wakix-epar-produ ct-information_en.pdf. Accessed May 2019.

16. Xyrem (sodium oxybate) information. US Food \& Drug Administration. https://www.fda.gov/drugs/postmarket-drug-safety-infor mation-patients-and-providers/xyrem-sodium-oxybate-informatio n. Accessed May 2019.

17. Alshaikh MK, Tricco AC, Tashkandi M, et al. Sodium oxybate for narcolepsy with cataplexy: systematic review and meta-analysis. J Clin Sleep Med JCSM Off Publ Am Acad Sleep Med. 2012;8:451-8.

18. Arnold SR, Straus SE. Interventions to improve antibiotic prescribing practices in ambulatory care. Cochrane Database Syst Rev. 2005;2005(4):CD003539.

19. Grimshaw J, Thomas R, MacLennan G, Fraser C, Ramsay C. Effectiveness and efficiency of guideline dissemination and implementation strategies. Health Technol Assess 2004;8(6)

20. O'Brien MA, Rogers S, Jamtvedt G, et al. Educational outreach visits: effects on professional practice and health care outcomes. Cochrane Database Syst Rev. 2007;2007(4):CD000409. 